\title{
Corporeidade e sexualidade em dançarinos de rua: axé e hip hop
}

CDD. 20.ed. 301.418

616.89

793

\author{
Fernando Luiz CARDOSO* \\ Rozana Aparecida SILVEIRA* \\ Cinara SACOMORI* \\ Fabiana Flores SPERANDIO* \\ Thais Silva BELTRAME*
}

*Centro de Ciências da

Saúde e do Esporte,

Universidade do Esta-

do de Santa Catarina.

\section{Resumo}

Analisaram-se aspectos da corporeidade e sexualidade em dançarinos de hip hop e axé (35 homens e 49 mulheres) comparativamente a indivíduos não-dançarinos expectadores da plateia (21 homens e 19 mulheres), via questionário anônimo. Os dançarinos de axé foram os mais satisfeitos com suas vidas sexuais, com as preliminares sexuais e os que mais gostavam de se masturbarem em relação aos de hip hop e plateia. Dançarinos do axé apresentaram uma sexualidade mais vinculada ao conhecimento corporal e conexões afetivas. Em ambos estilos, os dançarinos homens davam maior ênfase à genitália e a libido em relação aos aspectos da afetividade.

Unitermos: Corpo; Sexo; Gênero; Dança.

\section{Introdução}

Este artigo trata-se de uma das poucas contribuições empíricas ao relevante trabalho de revisão de literatura: "Dance and sexuality: many moves" escrito por Judith Lynne Hanna (2010). A sua revisão sobre estudos em diferentes períodos históricos e culturas explorou a relação entre dança e sexualidade, e revelou o interesse de muitas disciplinas que utilizam diferentes concepçōes teóricas e métodos de investigação. Essa seria a contribuição da Educação Física que não tem dedicado muita atenção à dança como parte do movimento humano. Apesar de existir muito escrito sobre sexualidade e dança, são poucos os estudos que repliquem ou comparem estas teorias. HANNA (2010) nos chama a atenção para a urgência da produção de trabalhos empíricos que produzam dados quantitativos para melhor se entender como as expressōes e as identidades sexuais variam dentro da dança.

Em todo o período da evolução, a dança esteve presente nas culturas humanas expressando diferentes significados. Acredita-se que esta tenha as suas origens no "anthropos" humano, fazendo parte dos antigos cerimoniais de fertilidade. No processo da evolução social, os homens viviam num mundo de forças místicas e a dança servia como instrumento de coesão com as divindades (Hanna, 1999). Para todos os momentos especiais da vida, existiam danças adequadas para comemorar, lastimar e referendar a vida. Os dançarinos envolvidos nestes cerimoniais deixavam de ser simples mortais, transformavam-se em entes sagrados, inspirados e possuídos pelas várias divindades. Quando pesquisamos a vida social de qualquer grupo humano, dos mais simples aos mais complexos, descobrimos a dança como manifestação cultural que expressa uma determinada representação da organização social (HANNA, 1999). Diante destes cerimoniais e representaçôes sociais, a dança pode ser entendida como um mágico ritual, onde a trajetória histórica e as manifestações dos anseios dos povos, mostram-se claramente, em um contínuo inventar e reinventar de posturas e movimentos (Alves \& Dias, 2004).

Em nossa sociedade complexa de classes, a dança ainda continua tendo a mesma importância que teve nas culturas humanas mais simples. A estratificação social principalmente das zonas urbanas brasileiras, caracterizada por diferentes níveis de oportunidade social, produziu ícones culturais da nação brasileira, como o desfile de escola de samba, o samba cantado e dançado e as danças populares. Muito da riqueza cultural, musical e corporal advém desse conflito social de classes que por muito tempo foi silencioso e disfarçado. 
Recentemente o aumento da violência nas cidades brasileiras tem demonstrado que algo mudou no cenário nacional e não dá mais para esconder a desigualdade e a insatisfação social (FERraz, 2002/3). Nesse contexto, as atividades culturais, como a música, a dança e as artes plásticas propiciam a construção de laços de identidade, de partilhas das vivências cotidianas, onde o lazer pode servir de canal para a mudança de valores e possível construção da cidadania e da inclusão destes excluídos (MAUss, 1974; RecKZIEGEL \& STIGger, 2005).

Assim, quando observamos uma apresentação de dança, estamos assistindo a uma releitura de como se expressa a organização social de um determinado grupo, que segundo o sociólogo BoHnsack (1999) tem espaço e tempo definido. As conhecidas danças de rua de hoje, como o "rap", o "funk" e o "break" tiveram sua origem nos tradicionais guetos negros norte-americanos como forma de protesto e rebeldia (Reckziegel \& Stigger, 2005; Strazzacappa, 2001). Já a "dança de rua baiana" surgiu de forma espontânea nos guetos negros e pobres das periferias da grande Salvador, mas com uma motivação diferente, focada na diversão e lazer. É uma dança que tem uma forte herança africana e identifica nos passos dançados muitos movimentos dos orixás (Robatto, 2006).

Mais tarde, o "break" e a dança de rua baiana saem do espaço público e anônimo das ruas para as academias de dança com um formato mais pasteurizado que os coloca hoje como mais dois estilos de dança consumidos pela clientela fitness: o hip hop e o axé (ALVES \& DiAs, 2004). Estes dois estilos de dança manifestam-se através da musicalidade (RAMOS, 2001).

Apesar da apropriação do hip hop e do axé pelo grande mercado em expansão do "fitness", estes ainda guardam muito do contexto de onde surgiram. Esta herança pode ser percebida pela personalidade dos movimentos e técnicas corporais de cada estilo. $\mathrm{O}$ axé e o hip hop podem ser considerados como técnicas corporais específicas. O antropólogo

\section{Procedimentos metodológicos}

Esta é uma pesquisa de campo caracterizada como descritiva comparativa que teve como desenho a comparação da auto-avaliação da identidade corporal de dançarinos de dois estilos de dança em relação a um grupo controle que não praticava dança. Participaram deste estudo 35 dançarinos homens e 49 dançarinas
Marcel Mauss (1974), sugere que uma técnica corporal pode ser chamada de técnica, mesmo que seja aprendida espontaneamente e transmitida informalmente, como fazendo parte da cultura local. Mauss classifica como técnica corporal, a maneira como os homens se servem de seus corpos dentro de um "ethos" social. E foi pela tradição da técnica corporal de expressar-se ritmicamente que o hip hop e o axé foram transmitidos espontaneamente, comunicando uma forma de contestar as injustiças do sistema com vestimentas largas e despojadas e de relaxar e se divertir com a malícia de vestimentas colante e "sexy" (RAMOS, 2001), respectivamente.

Acredita-se que a prática e convívio com estes dois estilos de dança modifica as formas de perceber a corporeidade e a sexualidade, como também estimula a elaboração de uma identidade corporal diferenciada e personificada em seus praticantes.

O conceito de corporeidade e sexualidade adotados neste estudo trata-se do conhecimento do corpo e do sexo em uma perspectiva filosófica, sem desconsiderar a sua dimensão biológica e associando-a ou integrando-a ao conceito de mente (CARDOSO, 1996; JoÃo \& BRITO, 2004). Assim, percebe-se uma grande aproximação do conceito de identidade do indivíduo com o de corporeidade (Assmann, 1995) e de sexualidade (CARdoso, 1996). Isto nos permite falar de uma identidade corporal do sujeito construída a partir destas duas dimensões: corporeidade e sexualidade.

Diante de tais considerações, questionamos em que medida dançar a exaltação aos valores de um grupo social e o repúdio a ordem dominante, ou dançar a exaltação a sensualidade e a volúpia da saúde e bem estar, podem afetar a corporeidade e a sexualidade de homens e mulheres dançarinos?

Nesse estudo, procuramos descrever e comparar as diferenças entre os dançarinos de axé e hip hop em termos de sexo, gênero, corporeidade e sexualidade. Enfim, gostaríamos de descrever e comparar e não apenas interpretar, alguns aspectos da identidade corporal dos participantes destes distintos estilos do dançar.

mulheres, além do grupo controle de 40 expectadores e apreciadores da dança (21 homens e 19 mulheres). A pesquisa foi realizada em dois momentos diferentes, a primeira no "Meeting" de hip hop da cidade de Indaiatuba-SP, onde houve competições, mostras e "workshop" de hip hop. Neste evento 24 grupos 
de vários estados estavam presentes e 36 dançarinos participaram da pesquisa. A segunda coleta foi realizada em uma academia na grande Florianópolis em um ensaio dos dançarinos de um grupo de axé. Participaram dessa coleta 48 dançarinos.

Esta pesquisa utilizou uma auto-avaliação por intermédio da primeira versão do Questionário de Identidade Corporal (QIC), constituído de três dimensões (sexualidade, corporeidade e motricidade). O termo identidade corporal refere-se a como alguém identifica ou reconhece o próprio corpo, estando, pois, dependente de um processo de percepção e cognição (Adami, Fernandes, Frainer \& Oliveira, 2005; Tavares, 2003; Urgesi, Candidi, Ionta \& Aglioti, 2007). No início do questionário constam aspectos gerais do pesquisado: idade, profissão, estado civil, sexo biológico, gênero e orientação sexual; e questóes sociais: que são os bens de consumo que o pesquisado possui em casa, o grau de escolaridade e a prática de atividade física. O questionário é composto por nove escalas: intimidade corporal, percepção corporal, satisfação corporal, identidade infantil, prédisposição sexual, comportamento sexual, orientação sexual, satisfação sexual, experiência motora e orientação motora. Cada escala é medida através de uma Escala Likert de quatro níveis (nunca - pouco - médio - muito, quantificados da seguinte forma: 0 - 1 - 2 - 3). O instrumento em sua versão atualizada encontra-se disponível online gratuitamente no endereço: http://www.cefid.udesc.br/laboratorios/ lagesc/instrumentos/Questionario-sobre-IdentidadeCorporal.pdf.
Esta pesquisa foi aprovada pelo Comitê de Ética em Pesquisa da Universidade do Estado de Santa Catarina, número 40/2005. Os dados da pesquisa foram inseridos e analisados no programa computadorizado "Statistical Package for the Social Science" (SPSS for Windows) versão 17.0. Realizou-se uma análise descritiva dos dados, análise de variância através do "One-Way" ANOVA para verificar diferenças entre os dois estilos de dança e o grupo controle e um teste $t$ de student para averiguar diferenças entre os dois sexos.

\section{Participantes}

Os participantes da pesquisa foram praticantes de dança (hip hop e axé) e público que prestigiava a dança, com mais de 18 anos de idade, de ambos os sexos. Os $56(45,2 \%)$ homens e $68(54,8 \%)$ mulheres que participaram da pesquisa possuíam idade mínima de 18 e máxima de 42 anos, ficando com uma média de idade de $23( \pm 4,1)$ anos, não existindo diferença significativa entre os três grupos. Quanto à escolaridade, os praticantes de hip hop tinham menos escolaridade, seguidos pelos praticantes de axé e pelos participantes do público que possuíam a maior escolaridade. Os dançarinos tinham maior poder de consumo e os dançarinos de hip hop se auto-avaliaram como mais masculinos em termos de identidade de gênero em relação aos participantes da plateia (TABELA 1). Quanto ao estado civil, a maioria dos participantes $(80 \%)$ era solteiro, não havendo diferenças significativas entre os grupos.

TABELA 1 - Perfil dos participantes da pesquisa.

\begin{tabular}{|c|c|c|c|c|c|c|c|c|}
\hline \multirow[t]{2}{*}{ Variáveis } & \multicolumn{2}{|c|}{$\begin{array}{c}\text { Hip Hop } \\
\mathrm{n}=36\end{array}$} & \multicolumn{2}{|c|}{$\begin{array}{c}\text { Axé } \\
\mathrm{n}=48\end{array}$} & \multicolumn{2}{|c|}{$\begin{array}{l}\text { Plateia } \\
\mathrm{n}=\mathbf{4 0}\end{array}$} & \multirow[t]{2}{*}{$F$} & \multirow[t]{2}{*}{$P$} \\
\hline & $X$ & sd & $X$ & sd & $X$ & sd & & \\
\hline Idade $^{1}$ & 23,17 & 5,4 & 22,04 & 3,5 & 24,15 & 4,6 & 2,29 & n.s. \\
\hline Grau de escolaridade ${ }^{2}$ & $3,17^{\mathrm{a}}$ & 1,3 & $4,38^{\mathrm{b}}$ & 1,1 & $5,15^{\mathrm{c}}$ & 0,4 & 34,17 & 0,001 \\
\hline Bens de consumo ${ }^{3}$ & $2,09^{\mathrm{b}}$ & 0,8 & $2,50^{\mathrm{b}}$ & 1,3 & $1,40^{\mathrm{a}}$ & 1,0 & 11,36 & 0,001 \\
\hline Gênero ${ }^{4}$ & $0,91^{\mathrm{a}}$ & 1,0 & $1,33^{\mathrm{b}}$ & 0,9 & $1,53^{\mathrm{b}}$ & 0,5 & 4,95 & 0,009 \\
\hline
\end{tabular}

\section{Resultados}

\section{Perfil sexual dos participantes}

Em termos de "orientação sexual" todos os dançarinos de hip hop se avaliaram heterossexuais.
Dentre os dançarinos de axé e os participantes da plateia, a maioria também se avaliou como heterossexuais, porém oito (17\%) e dois (4\%) indivíduos do axé se avaliaram bissexuais e
Sig. (2-tailed) $\leq 0,05$. ${ }^{1}$ Média da idade em anos;

${ }^{2}$ Média do grau de escolaridade entre sete niveis $(0$ - primeiro grau incompleto a 6 pós-graduação);

${ }^{3}$ Média de quatro itens de consumo;

${ }^{4}$ Média da auto-avaliação da identidade de gênero entre três níveis (0 - masculino, 1 - andrógino, 2 - feminino). 
homossexuais, respectivamente; e dois $(5 \%)$ indivíduos da plateia se avaliaram como homossexuais. Os participantes dos três grupos tiveram a sua primeira relação sexual em torno dos 15,6 anos ( \pm $2,8)$ não havendo diferenças significativas entre os grupos nesse aspecto. Os dançarinos de axé eram os mais satisfeitos com as suas vidas sexuais $(X=2,63 \pm$ $0,6)$ em relação aos dançarinos de hip hop e plateia $(X=2,19 \pm 1,1$ e $X=1,95 \pm 0,8$, respectivamente, sendo $F=6,763, p<0,002)$. Os dançarinos de axé também eram os mais satisfeitos com as preliminares sexuais $(X=2,78 \pm 0,6)$, seguidos pelos dançarinos de hip hop $(X=2,30 \pm 1,0)$ e pelos participantes $\mathrm{da}$ plateia $(X=1,86 \pm 0,9$, sendo $F=11,27, p<0,001)$. Os dançarinos de axé gostavam mais de se masturbar $(X=1,67 \pm 1,0)$ em relação aos participantes da plateia e dançarinos de hip hop $(X=1,03 \pm 0,7 \mathrm{e}$ $X=0,79 \pm 0,9$, respectivamente, sendo $\mathrm{F}=9,04$, $\mathrm{p}<0,001)$.

\section{Comparações entre os grupos controlado pelo sexo}

As mulheres dançarinas, além de se perceberem mais masculinas, conheciam melhor a sua genitália e estavam mais satisfeitas com a sua frequência sexual do que as participantes da plateia (TABELA 2). As dançarinas de hip hop faziam mais sexo anal e gostavam mais de variar de parceiros sexuais. Já as dançarinas de axé gostavam mais de beijo no sexo, valorizavam mais as carícias íntimas, faziam mais sexo oral no parceiro, tinham maior prontidão para o sexo, gostavam mais de sexo com romance, estavam mais satisfeitas com a vida sexual, gostavam mais de se masturbarem e se olhavam mais no espelho. Estas características nos ajudam a melhor caracterizar a sexualidade das dançarinas de axé como mais vinculada ao conhecimento corporal e conexōes afetivas.

TABELA 2 - Comparação das características da sexualidade das mulheres entre os três grupos de participantes (hip-hop, axé e plateia).

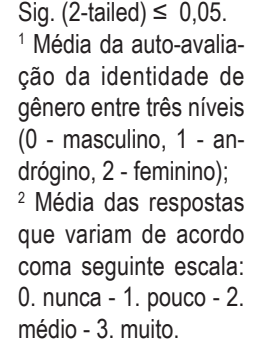

Sig. (2-tailed) $\leq 0,05$. ${ }^{1}$ Média da auto-avaliação da identidade de entre três niveis

${ }^{2}$ Média das respostas que variam de acordo 0 . nunca - 1. pouco - 2. médio - 3. muito.

\begin{tabular}{|c|c|c|c|c|c|c|c|c|}
\hline \multirow[t]{2}{*}{ Variáveis } & \multicolumn{2}{|c|}{$\begin{array}{c}\text { Hip Hop } \\
\mathbf{n}=36\end{array}$} & \multicolumn{2}{|c|}{$\begin{array}{c}\text { Axé } \\
n=48\end{array}$} & \multicolumn{2}{|c|}{$\begin{array}{c}\text { Plateia } \\
\mathrm{n}=40\end{array}$} & \multirow[t]{2}{*}{$F$} & \multirow[t]{2}{*}{$P$} \\
\hline & $X$ & $s d$ & $X$ & $s d$ & $X$ & $s d$ & & \\
\hline \multicolumn{9}{|l|}{ Influência da prática da dança } \\
\hline Nível de masculinidade $^{1}$ & $2,00^{\mathrm{a}}$ & 0,0 & $1,88^{\mathrm{a}}$ & 0,5 & $1,00^{\mathrm{b}}$ & 0,0 & 50,46 & 0,001 \\
\hline Conhece a sua genitália ${ }^{2}$ & $2,20^{a}$ & 0,9 & $2,47^{a}$ & 0,8 & $1,11^{\mathrm{b}}$ & 0,9 & 14,93 & 0,001 \\
\hline Satisfeito com frequência sexual ${ }^{2}$ & $1,93^{\mathrm{a}}$ & 1,2 & $2,35^{a}$ & 0,8 & $1,37^{\mathrm{b}}$ & 0,8 & 7,54 & 0,001 \\
\hline \multicolumn{9}{|l|}{ Mapa amoroso } \\
\hline Faço sexo anal ${ }^{2}$ & $1,87^{\mathrm{a}}$ & 1,3 & $0,35^{\mathrm{c}}$ & 0,6 & $1,17^{\mathrm{b}}$ & 1,0 & 14,55 & 0,001 \\
\hline Gosto de variar parceiros sexuais ${ }^{2}$ & $2,43^{\mathrm{a}}$ & 1,0 & $0,44^{\mathrm{b}}$ & 0,6 & $0,53^{\mathrm{b}}$ & 0,6 & 38,43 & 0,001 \\
\hline Gosto de beijo no sexo ${ }^{2}$ & $0,43^{c}$ & 0,9 & $2,47^{a}$ & 0,9 & $1,39^{\mathrm{b}}$ & 1,1 & 24,06 & 0,001 \\
\hline Valorizo caricias íntimas ${ }^{2}$ & $2,14^{b}$ & 1,0 & $3,00^{\mathrm{a}}$ & 0,0 & $1,79^{c}$ & 0,4 & 33,64 & 0,001 \\
\hline Eu faço oral no parceiro ${ }^{2}$ & $0,40^{\mathrm{b}}$ & 0,6 & $1,88^{a}$ & 1,0 & $1,95^{\mathrm{a}}$ & 1,0 & 13,46 & 0,001 \\
\hline Prontidão para o sexo ${ }^{2}$ & $0,27^{b}$ & 0,6 & $2,47^{a}$ & 0,5 & $2,16^{a}$ & 0,8 & 65,61 & 0,001 \\
\hline Gosta de sexo com romance ${ }^{2}$ & $0,67^{b}$ & 0,9 & $2,88^{\mathrm{a}}$ & 0,3 & $2,67^{b}$ & 0,8 & 26,95 & 0,001 \\
\hline Satisfeito com a vida sexual ${ }^{2}$ & $1,33^{\mathrm{b}}$ & 1,2 & $2,65^{a}$ & 0,6 & $1,74^{\mathrm{b}}$ & 0,8 & 7,54 & 0,001 \\
\hline Eu gosto de me masturbar ${ }^{2}$ & 0,86 & 0,9 & $1,41^{a}$ & 1,0 & $0,65^{\mathrm{b}}$ & 0,7 & 4,73 & 0,010 \\
\hline Eu me olho no espelho ${ }^{2}$ & $2,13^{a}$ & 0,8 & $2,71^{\mathrm{b}}$ & 0,7 & $2,63^{\mathrm{b}}$ & 0,8 & 3,11 & 0,050 \\
\hline
\end{tabular}

Os homens dançarinos, além de se perceberem mais masculinos, controlavam melhor o momento do orgasmo, gostavam mais de sexo no primeiro encontro e gostavam mais de variar de parceiros sexuais que os participantes da plateia (TABELA 3). Os dançarinos de hip hop fazem e gostavam mais de sexo anal. Já os dançarinos de axé gostavam mais de abraço no sexo, se automassageavam mais, gostavam mais de sexo, gostavam mais de se masturbarem, se olhavam mais no espelho, tinham maior prontidão para o sexo, tocavam mais os seus corpos por inteiro, gostavam mais de beijo no sexo e se achavam mais 
“sexy”. Estas características, assim como nas mulheres, nos ajudam a melhor caracterizar a sexualidade dos dançarinos de axé como mais vinculadas ao conhecimento corporal e conexões afetivas.

TABELA 3 - Comparação das características da sexualidade dos homens entre os três grupos de participantes (hip-hop, axé e plateia).

\begin{tabular}{|c|c|c|c|c|c|c|c|c|c|}
\hline \multirow{2}{*}{ Variáveis } & \multicolumn{2}{|c|}{ Hip Hop } & \multicolumn{2}{|c|}{ Axé } & \multicolumn{2}{|c|}{ Plateia } & \multirow{2}{*}{$F$} & \multirow{2}{*}{$P$} & \multirow{21}{*}{$\begin{array}{l}\text { Obs. Sig. (2-tailed) } \leq \\
0.05 \text {. } \\
{ }^{1} \text { Média da auto-avalia- } \\
\text { ção da identidade de } \\
\text { gênero entre três níveis } \\
\text { (0 - masculino, } 1 \text { - an- } \\
\text { drógino, } 2 \text { - feminino); } \\
{ }^{2} \text { Média das respostas } \\
\text { que variam de acordo } \\
\text { coma seguinte escala: } \\
\text { 0. nunca - 1. pouco - } 2 \text {. } \\
\text { médio - 3. muito. }\end{array}$} \\
\hline & $X$ & $s d$ & $X$ & $s d$ & $X$ & $s d$ & & & \\
\hline \multicolumn{10}{|l|}{ Influência da prática da dança } \\
\hline Nível de masculinidade $^{1}$ & $0,10^{\mathrm{a}}$ & 0,4 & $0,00^{\mathrm{a}}$ & 0,0 & $2,00^{\mathrm{b}}$ & 0,0 & 335,26 & 0,001 & \\
\hline Controla o orgasmo ${ }^{2}$ & $2,72^{\mathrm{a}}$ & 0,4 & $2,43^{\mathrm{a}}$ & 0,5 & $1,71^{\mathrm{b}}$ & 0,9 & 9,61 & 0,001 & \\
\hline Gosta de sexo no primeiro encontro ${ }^{2}$ & $2,25^{\mathrm{a}}$ & 0,8 & $2,43^{\mathrm{a}}$ & 0,7 & $1,56^{\mathrm{b}}$ & 0,9 & 7,77 & 0,001 & \\
\hline Gosta de variar parceiros ${ }^{2}$ & $2,55^{\mathrm{a}}$ & 0,8 & $2,29^{a}$ & 1,0 & $0,94^{\mathrm{b}}$ & 1,0 & 13,98 & 0,001 & \\
\hline Mapa amoroso & & & & & & & & & \\
\hline Faço sexo anal ${ }^{2}$ & $2,86^{\mathrm{a}}$ & 0,3 & $1,57^{b}$ & 1,3 & $0,83^{\mathrm{c}}$ & 0,8 & 26,60 & 0,001 & \\
\hline Gosto de penetração anal ${ }^{2}$ & $2,80^{\mathrm{a}}$ & 0,7 & $2,14^{b}$ & 1,1 & $1,35^{\mathrm{c}}$ & 0,9 & 11,32 & 0,001 & \\
\hline Considera abraço sexo ${ }^{2}$ & $0,63^{\mathrm{b}}$ & 0,8 & $1,71^{\mathrm{a}}$ & 1,3 & $0,61^{\mathrm{b}}$ & 0,9 & 5,43 & 0,007 & \\
\hline Me automassageio ${ }^{2}$ & $1,15^{b}$ & 0,9 & $2,14^{\mathrm{a}}$ & 1,0 & $1,00^{\mathrm{b}}$ & 0,7 & 7,17 & 0,002 & \\
\hline Eu gosto de sexo ${ }^{2}$ & $1,60^{\mathrm{b}}$ & 0,7 & $3,00^{\mathrm{a}}$ & 0,0 & 2,84 & 0,4 & 40,41 & 0,001 & \\
\hline Eu gosto de me masturbar ${ }^{2}$ & $0,74^{\mathrm{c}}$ & 1,0 & $2,29^{\mathrm{a}}$ & 1,1 & $1,41^{\mathrm{b}}$ & 0,7 & 10,65 & 0,001 & \\
\hline Eu me olho no espelho ${ }^{2}$ & $1,95^{\mathrm{b}}$ & 0,9 & $2,86^{\mathrm{a}}$ & 0,4 & $1,84^{\mathrm{b}}$ & 1,1 & 5,95 & 0,005 & \\
\hline Prontidão para o sexo ${ }^{2}$ & $1,85^{b}$ & 0,9 & $2,86^{\mathrm{a}}$ & 0,4 & $2,55^{\mathrm{a}}$ & 0,6 & 9,48 & 0,001 & \\
\hline Toco meu corpo por inteiro ${ }^{2}$ & $1,72^{\mathrm{b}}$ & 0,8 & $2,86^{\mathrm{a}}$ & 0,4 & $1,63^{\mathrm{b}}$ & 0,9 & 11,50 & 0,001 & \\
\hline Gosto de beijo no sexo ${ }^{2}$ & $1,79^{\mathrm{b}}$ & 1,1 & $2,71^{\mathrm{a}}$ & 0,4 & $2,06^{\mathrm{b}}$ & 0,8 & 4,26 & 0,02 & \\
\hline Acha corpo "sexy"2 & $2,20^{\mathrm{b}}$ & 0,4 & $2,71^{\mathrm{a}}$ & 0,5 & 2,16 & 0,8 & 3,53 & 0,04 & \\
\hline Eu me masturbo ${ }^{2}$ & $1,55^{\mathrm{b}}$ & 0,8 & $2,29^{a}$ & 0,9 & $1,62^{\mathrm{b}}$ & 1,0 & 3,14 & 0,05 & \\
\hline Eu me acho "sexy"2 & $1,84^{\mathrm{b}}$ & 0,6 & $2,43^{\mathrm{a}}$ & 0,5 & 2,06 & 0,7 & 3,53 & 0,04 & \\
\hline Vida sexual com parceiro fixo ${ }^{2}$ & $1,90^{\mathrm{b}}$ & 1,0 & $2,71^{a}$ & 0,5 & $2,05^{\mathrm{b}}$ & 1,0 & 3,29 & 0,04 & \\
\hline
\end{tabular}

\section{Comparações da corporeidade e sexualidade entre homens e mulheres dançarinos}

$\mathrm{Na}$ TABELA 4 são apresentadas as principais diferenças entre os sexos em termos de corporeidade e sexualidade. As mulheres, de forma geral, iniciaram a sua vida sexual mais tarde que os homens. Além disso, os dançarinos homens gostavam mais de assistir filmes eróticos, se interessavam mais facilmente por sexo, gostavam mais de penetração anal, faziam mais sexo no primeiro encontro, gostavam mais de sexo sem compromisso, se excitavam mais facilmente e tinham mais parceiros sexuais. Todas estas diferenças mostram, em termos médios, como os homens são mais focados em suas genitálias e dão maior ênfase sexual à libido que à afetividade. 
TABELA 4 - Diferenças na corporeidade e sexualidade entre dançarinos homens e mulheres.

Sig. (2-tailed) $\leq 0,05$. ${ }^{1}$ Média da idade em que teve a primeira relação sexual com um parceiro/a;

${ }^{2}$ Média das respostas que variam de acordo coma seguinte escala: 0 . nunca - 1. pouco - 2. médio - 3. muito.

\begin{tabular}{|c|c|c|c|c|c|c|}
\hline \multirow{2}{*}{ Variáveis } & \multicolumn{2}{|c|}{ Homens } & \multicolumn{2}{|c|}{ Mulheres } & \multirow{2}{*}{$t$} & \multirow{2}{*}{$P$} \\
\hline & $X$ & $s d$ & $X$ & $s d$ & & \\
\hline Idade da primeira relação sexual $^{1}$ & 14,81 & 2,1 & 16,45 & 2,1 & $-3,03$ & 0,001 \\
\hline Conhece a sua genitália² & 2,87 & 0,4 & 2,39 & 0,8 & 2,97 & 0,004 \\
\hline Gosta de filmes eróticos ${ }^{2}$ & 1,85 & 1,0 & 1,02 & 0,9 & 3,60 & 0,001 \\
\hline Facilmente me interesso por sexo ${ }^{2}$ & 2,79 & 0,5 & 2,27 & 0,8 & 3,50 & 0,001 \\
\hline Gosta de penetração anal ${ }^{2}$ & 2,53 & 0,9 & 1,06 & 1,2 & 5,76 & 0,001 \\
\hline Faz sexo no primeiro encontro ${ }^{2}$ & 1,39 & 1,0 & 0,35 & 0,6 & 6,06 & 0,001 \\
\hline Gosta de sexo sem compromisso ${ }^{2}$ & 1,68 & 1,1 & 0,78 & 1,0 & 3,54 & 0,001 \\
\hline Facilmente me excito sexualmente ${ }^{2}$ & 2,26 & 0,9 & 1,80 & 1,1 & 4,84 & 0,001 \\
\hline Ter vários parceiros sexuais ${ }^{2}$ & 2,44 & 0,9 & 1,04 & 1,2 & 3,82 & 0,001 \\
\hline
\end{tabular}

\section{Discussão}

Considerando-se a pouca frequência de homens praticantes de dança (VAN DYKE, 1996), este trabalho encontrou alta frequência de homens praticantes de axé e hip hop nos grupos estudados, similar ao encontrado na pesquisa de Cardoso, Silveira, Zequinão, Martins e SouzA (2010). Provavelmente, tal substancial presença masculina nesses estilos deva-se a uma percepção social mais masculinizada do hip hop e do axé em relação aos demais estilos de dança. Nesse sentido, foi avaliada a percepção social da identidade de gênero dos estilos de dança na ótica dos profissionais que lecionam dança e os mesmos consideraram o hip hop, o axé e a dança de salão como os estilos mais congruentes com o estereótipo de masculinidade em nossa sociedade (CARDOSO, Silveira, Sacomori \& Zequinão, 2010).

HERSCHMANN (2000) também chama a atenção para o papel assimétrico e secundário que a mulher desempenha no movimento hip hop. As mulheres vivenciam situações de exclusão que acontecem tanto na música, como na dança desse estilo. Até mesmo a plasticidade física e as roupas utilizadas pelas mulheres no dançar são semelhantes às dos homens. Provavelmente, tais aspectos devam aproximar-se de um olhar mais masculino nesse estilo.

Em relação ao axé, essa procura masculina pode ser explicada pelo relato do precursor da dança baiana, Antônio Cozido em entrevista a RoBATTO e MASCARENHAS (2002), afirmando que os homens ao dançarem, conseguem, além de se divertir, conquistar às mulheres com mais facilidade. Além disso, sugere que os primeiros grupos de homens nesse estilo foram formados com o apoio feminino.
De acordo com RoBATTO (2006), a característica da presença do homem na dança é peculiar da cultura espontânea. Nas manifestaçôes culturais como terno de reis, maracatu ou o samba de roda, assim como nas demais danças de rua, é frequente a presença masculina. Já, no ensino formal, como nas universidades e academias de balé, existem poucos homens matriculados, a ponto de se oferecer, em alguns locais, a gratuidade do curso, como forma de estímulo à participação dos mesmos.

Além disso, para Novaes (2002), a rua é um lugar de violência, criminalidade, perigo, estando completamente associada ao mundo masculino. Neste sentido, explica-se o maior número de homens neste grupo de dança pesquisado.

Neste estudo, percebemos que os praticantes de hip hop têm uma menor escolaridade, o que provavelmente explica uma origem social mais humilde ou uma menor influência do capital cultural da classe média profissional que privilegia a educação. Chegamos a estas duas possibilidades pelo fato de que os dançarinos têm, em média, mais acesso ao consumo do que os participantes da plateia, apesar desses, terem maior escolaridade. Enfim, esta pesquisa estudou dois estilos de dança que são caracterizados por serem movimentos sociais ligados à juventude, em que poucos desses jovens eram casados, exprimindo um estilo de vida que provavelmente influenciará a construção da identidade de seus participantes (FLEURY, 2007; Stoppa \& Marcellino, 2006). 


\section{Perfil sexual dos três grupos}

Quanto à "orientação sexual” dos participantes da pesquisa, a maioria se classificou como heterossexual, porém uma pequena porcentagem se declarou homossexual e bissexual entre os dançarinos de axé e participantes da plateia. Um estudo mostrou menor incidência de homo e bissexuais no hip hop e axé em relação a outros estilos de dança (CARDOso et al., 2010).

Em termos de identidade de gênero, os resultados demonstraram que a maioria dos homens se considerou masculino e as mulheres femininas, como esperado. Para Cardoso (1994), o gênero constitui-se na identidade do corpo, referindo-se as origens eminentemente sociais, sendo a fisiologia e a biomecânica humana um aspecto biológico, enquanto o dançarino e a personalidade de seus movimentos é uma construção humana e social. Neste sentido, a prática do hip hop e do axé parece masculinizar ligeiramente a identidade de gênero das mulheres praticantes e, de forma inesperada, também masculiniza a identidade de gênero dos próprios homens.

Coutinho (2005) fez uma pesquisa com estudantes universitários do Rio de Janeiro, de ambos os sexos, entre 18 a 28 anos. A autora verificou que homens e mulheres oscilaram muito entre os dois modelos idealizados de masculino e feminino, o tradicional que indica a separação das esferas de atuação dos sexos e o moderno, que expressa a divisão de direitos e deveres. Porém, como o gênero costuma ser muito associado à orientação sexual, talvez os participantes tenham sido tendenciosos ao classificarem-se como do mesmo gênero, por medo de serem considerados homossexuais. Em nosso estudo, essa tendência pode ter ocorrido com os participantes homens que podem ter recebido esse tipo de influência dos estereótipos sexuais em suas avaliaçóes, no entanto, as mulheres parecem não ter apresentado esse tipo de dificuldade, pois se auto-avaliaram como mais masculinas.

Os dançarinos de axé confirmaram parte dos estigmas relacionados à sensualidade que está vinculada a este estilo de dança, quando comparado aos praticantes de hip hop e, provavelmente, as demais modalidades de dança. Isso foi constatado porque estavam mais satisfeitos com as preliminares sexuais e com a sua vida sexual de forma geral, além de ter maior contato com a sua própria sexualidade via maior satisfação na prática do sexo solitário.

\section{Diferenças entre os estilos de dança}

Ao analisarmos os dados do QIC dos dançarinos de rua que participaram desta pesquisa, observamos que a percepção do senso comum em relação ao axé como o estilo de dança com maior apelo sensual procede. Os dançarinos e dançarinas desse estilo mostraram escores superiores em itens que indicam um maior conhecimento e intimidade corporal e sexual. A sexualidade do dançarino de axé mostra-se mais fluída e dispersa corporalmente, além de valorizar aspectos mais afetivos no ato sexual. Infelizmente, não encontramos estudos que tenham comparado de forma quantitativa tais comportamentos entre dançarinos de rua.

CARdoso et al. (2010) encontraram uma vinculação entre os praticantes de hip hop de ambos os sexos e o gosto pela prática de artes marciais, pelas atividades físicas mais complexas e pelo fato de terem, na infância, se imaginado como destaques ou campeões em eventos esportivos. Esse perfil específico do desenvolvimento da corporeidade de praticantes de hip hop poderia explicar, em parte, uma sexualidade mais pragmática e mais focada na genitália.

\section{Diferenças na corporeidade e sexualidade entre os sexos}

Para entendermos melhor a sexualidade de homens e mulheres, faz-se necessário recorrer ao conceito de "Love Maps", ou seja, "mapas amorosos". Money (1986) define "mapas amorosos" como um esquema desenvolvimentista ou arquétipo na mente e no cérebro do amor idealizado, onde está projetada a atividade sexo/erótica do indivíduo. Money entende por mapa normofílico aquele típico da maioria da população, em que se consegue articular amor e sexo em um mesmo objeto de prazer, ou seja, em uma mesma pessoa. O mapa amoroso normofílico também apresenta diferentes níveis dessa articulação entre amor e sexo. Algumas pessoas não conseguem separar esses dois aspectos, estando, portanto, a atividade sexual relacionada ao amor, enquanto outras, conseguem distinguir e vivenciar o sexo em algumas situações específicas.

A diversidade de mapas amorosos trata-se de algo típico da nossa espécie, sendo que as mulheres tendem a ter uma maior sobreposição entre o erótico e o amor em comparação aos homens, os quais conseguem com maior facilidade distinguí-los e vivenciá-los com maior ou menor sobreposição. Cabe ressaltar que diferenças entre homens e mulheres 
nesses quesitos podem ser fortemente influenciadas por questôes socioeconômicas distintas, o que nem sempre é controlado ou verbalizado voluntariamente em pesquisas desta natureza.

Nas variáveis que mensuram o interesse por sexo, a importância do sexo, prontidão para o sexo, ênfase na variabilidade de parceiros sexuais, dentre outros, os homens, como esperado, tiveram maiores escores que as mulheres. SALEM (2006) relata a maior dissociação entre o sexo e o afeto/vínculo para os homens; obtido por entrevista a 123 sujeitos entre 18 a 24 anos pertencentes às classes popular e média.

Cardoso, Savall, Sabbag, Mendes e BeltraME (2009) ao estudarem os mapas amorosos em uma competição lúdica esportiva organizada para as minorias sexuais com grande diversidade de identidades sexuais em Florianópolis, perceberam que independentemente de orientação sexual, os participantes do sexo masculino e do sexo feminino apresentam mapas amorosos típicos para cada sexo, conforme Money já havia anteriormente proposto.

Portanto, as mulheres participantes dessa pesquisa, apesar de apresentarem características próprias de cada estilo, sustentam os preceitos teóricos de

\section{Considerações finais}

Os resultados do presente estudo nos permitem dizer que existem claras diferenças entre dançarinos de axé e hip hop em termos de corporeidade e sexualidade. Os praticantes de ambos os sexos de hip-hop e axé tiveram uma percepção da identidade de gênero tendendo a ser mais masculina.

Os praticantes de axé se percebem mais sensuais e mais satisfeitos sexualmente que os do hip-hop, denotando um maior conhecimento e intimidade corporal dos primeiros. Tal cultura corporal vivenciada na prática do axé estimula seus praticantes, inclusive os homens, a expressarem-se mais afetivamente. Em contrapartida, os praticantes de hip-hop, com suas expressões corporais mais agressivas ou rudes, enfatizam uma indignação perante as injustiças sociais, transferindo para a sexualidade uma
Money (1986) quando mostram uma maior conexão entre a libido e a afetividade.

O padrão sexual mais diversificado dos homens é avaliado pelos evolucionistas como herança do processo evolutivo da nossa espécie, sendo que pode estar baseado na necessidade de cultivar laços de superioridade com o objetivo de adquirir mais "status" social e acesso às mulheres, tendendo a comportamento de auto-afirmação social (BAKER, 1996).

Aqui, mais uma vez, poderíamos inferir algum tipo de influência da prática do axé ou do hip hop, pois os participantes homens dessa pesquisa confirmam as expectativas da literatura, mas ao mesmo tempo nos mostram como a prática do axé em detrimento da prática do hip hop produz dançarinos homens com mapas amorosos mais semelhantes as das praticantes mulheres.

GiaVONI (2000) chama a atenção para o fato de serem escassos estudos sobre o tema, sendo que os existentes não avaliam a relação entre homens e mulheres e, muito menos, a relação corporeidade e sexualidade. Sabe-se, que a prática da dança de rua exercita a ludicidade e a corporeidade e, ajuda os jovens praticantes a construírem, concomitantemente, a identidade e a socialização (FLEURY, 2007).

percepção mais pragmática e funcional centrada na relação pênis-vagina.

Desse modo, observou-se que a tradicional dicotomia entre mapas amorosos femininos e masculinos não esteve presente nos homens praticantes de axé, uma vez que estes, apesar de se perceberem como masculinos e heterossexuais, assumiram um mapa amoroso mais sobreposto, comum, até então, em mulheres.

Infelizmente, não é possível afirmar se os resultados encontrados neste estudo sejam reflexo da prática de cada estilo de dança ou se indivíduos com características específicas procuraram por estilos de dança que melhor combinassem com suas personalidades. Por fim, percebe-se a necessidade de estimular mais estudos quantitativos e explicativos - e não apenas interpretativos - na área da Educação Física e Dança. 


\begin{abstract}
Bodyness and sexuality of street dancers: axé and hip hop

We analyzed selected aspects of the bodyness and sexuality of hip hop and axé dancers (35 men and 49 women) in comparison with non-dancer controls (21 men and 19 women) through anonymous questionnaire. The axé dancers were the most satisfied with their sexual lives, with sexual preliminaries and who liked more to masturbate when compared with the hip hop dancers and controls. Axé dancers of both sexes presented a strong link between their sexuality and their corporal knowledge and affective connections. Men dancers were more focused in their genitals and gave stronger sexual emphasis to libido rather than affectivity.
\end{abstract}

UnITERMS: Body; Sex; Gender; Dance.

\title{
Referências
}

ALVES, F.S.; DIAS, R. A dança break: corpos e sentidos em movimento no hip hop. Motriz, Rio Claro, v.10, n.1, p.1-7, 2004. ADAMI, F.; FERNANDES, T.C.; FRAINER, D.E.S.; OLIVEIRA, F.R. Aspectos da construção e desenvolvimento da imagem corporal e implicações na educação física. Lecturas, Educación Física y Deportes: Revista Digital, Buenos Aires, ano 10, n.83, 2005. Disponível em: <http://www.efdeportes.com/efd83/imagem.htm>.

ASSMANN, H. Paradigmas educacionais e corporeidade. São Paulo: UNIMEP, 1995.

BAKER, R. Sperm wars: the science of sex. New York: Harper Collins, 1996.

BOHNSACK, R. Rekonstruktive Sozialforschung: Einführung in Methodologie und Praxis qualitativer Forschung. Opladen: Leske + Budrich, 2003.

CARDOSO, F.L. O gênero e o movimento humano. Revista Brasileira de Ciências do Esporte, Santa Maria, v.15, n.3, p.265-8, 1994.

O que é orientação sexual? São Paulo: Brasiliense, 1996.

CARDOSO, F.L.; SAVALL, A.C.; SABBAG, S.; MENDES, A.K.; BELTRAME, T.S. Implicações do conhecimento corporal no comportamento sexual. Revista Brasileira de Educação Física e Esporte, São Paulo, v. 23, p. 345-354, 2009. CARDOSO, F.L.; SILVEIRA, R.A.; SACOMORI, C.; ZEQUINÃO, M. Identidade de gênero nos diferentes estilos de dança. Florianópolis: Universidade do Estado de Santa Catarina, 2010. (Relatório de Pesquisa não publicado).

CARDOSO, F.L.; SILVEIRA, R.A.; ZEQUINĀO, M.; MARTINS, C. P.; SOUZA, C.A. Auto-percepção corporal e preferências motoras de praticantes de dança. Movimento, Porto Alegre, v.16, n.1, p.75-80, 2010.

COUTINHO, M.P.L. Depressão infantil e representação social. João Pessoa: Universitária, 2005.

FERrAZ, T.G. Cotidiano e dança na periferia: reflexōes para uma prática educativa. Pensar a Prática, Goiânia, v.6, p.117-38, 2002/2003.

FLEURY, M.M.N. Dança de rua: jovens entre projetos de lazer e trabalho. Última Década, Valparaíso, v. 27, p.27-48, 2007. GIAVONI, A. A interação entre os esquemas masculino e feminino do autoconceito: modelo interativo. Tese (Doutorado). Brasília: Universidade de Brasília, 2000.

HANNA, J.L. Dança, sexo e gênero. Rio de Janeiro: Rocco, 1999.

. Dance and sexuality: many moves. Journal of Sex Research, New York, v.47, n.2/3), p.212-41, 2010.

HERSCHMANN, M. O funk e hip-hop invadem a cena. Rio de Janeiro: Editora UFRJ, 2000.

JOÃO, R.B.; BRITO, M. Pensando a corporeidade na prática pedagógica em educação física à luz do pensamento complexo. Revista Brasileira de Educação Física e Esporte, São Paulo, v.18, n.3, p.263-72, 2004.

MAUSS, M. Sociologia e antropologia. São Paulo: Pedagógica e Universitária, 1974.

MONEY, J. Love maps: clinical concepts of sexuallerotic health and pathology, paraphilia, and gender transposition in childhood, adolescence, and maturity. New York: Irvington, 1986.

NOVAES, R. Hip hop: o que há de novo? In: PERSPECTIVAS de gênero: debates e questōes para as ONGs. Recife: GT Gênero/Plataforma de Contrapartes Novib/SOS CORPO Gênero e Cidadania, 2002.

RAMOS, F.P. O que é documentário. In: ESTUDOS de cinema 2000 SOCINE. Porto Alegre: Sulina, 2001. 
RECKZIEGEL, A.C.C.; STIGGER, M.P. Dança de rua: opção pela dignidade e compromisso social. Movimento, Porto Alegre, v 11, n.2, p.59-73, 2005.

ROBATTO, L. Um olhar sobre a cultura brasileira: dança. Disponível em: <www.minc.gov.br/textos/olhar/danca/>. Acesso em : 23 set. 2006.

ROBATTO, L.; MASCARENHAS, L. Passos da dança Bahia. Salvador: Casa de Palavras Memória, 2002.

SALEM, T. Tensões entre gêneros na classe popular: uma discussão com o paradigma holista. MANA, Rio de Janeiro, v.12, n.2, p.419-47, 2006.

STOPPA, E.A.; MARCELLINO, N.C. Hip-hop, lazer e participação sociocultural. Licere, Belo Horizonte, v. 9, n.2, p. 34-52, 2006.

STRAZZACAPPA, M. A educação e a fábrica de corpos: a dança na escola. Cadernos Cedes, Campinas, n. 53, p.69-83, 2001. TAVARES, M.C. Imagem corporal: conceito e desenvolvimento. Barueri: Manole, 2003.

URGESI, C.; CANDIDI, M.; IONTA, S.; AGLIOTI, S.M. Representation of body identity and body actions in extrastriate body area and ventral premotor cortex. Natural Neurocience, Washington, v.10, p.30-1, 2007.

VAN DYKE, J. Gender and success in the american dance world. Women's Studies International Forum, Highfield, v.19, n.5, p.535-43, 1996.

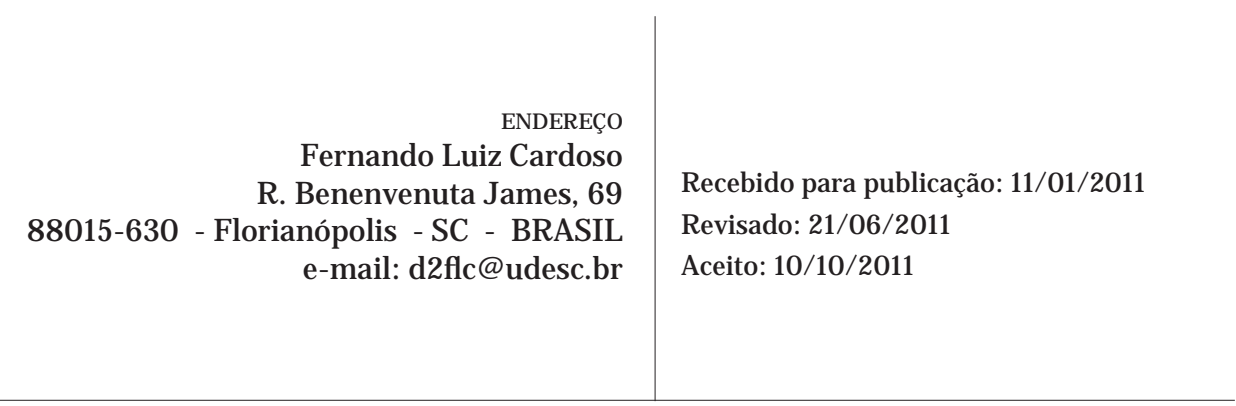

672 • Rev. bras. Educ. Fís. Esporte, São Paulo, v.25, n.4, p.663-72, out./ dez. 2011 